\title{
Influence of Simulated Pulpal Pressure on Efficacy of Bleaching Gels
}

\author{
${ }^{1}$ Alessandra Bühler Borges, ${ }^{2}$ Graziela Ribeiro Batista, ${ }^{3}$ Paula Tamião Arantes, ${ }^{4}$ Annette Wiegand \\ ${ }^{5}$ Thomas Attin, ${ }^{6}$ Carlos Rocha Gomes Torres
}

\section{ABSTRACT}

Aim: The aim of this study was to investigate the influence of simulated pulpal pressure on efficacy of bleaching gels.

\begin{abstract}
Materials and methods: Cylindrical enamel-dentin specimens from bovine teeth ( $3 \mathrm{~mm}$ diameter, enamel and dentin layer each $1 \mathrm{~mm}$ thick) were divided into 4 groups, according to the bleaching treatment: negative control (non-bleached), bleached with $10 \%$ carbamide peroxide (CP), bleached with $7.5 \%$ hydrogen peroxide (HP) and bleached with $35 \%$ hydrogen peroxide. Ten percent CP gel was applied for $8 \mathrm{~h} /$ day and $7.5 \%$ $\mathrm{HP}$ for $1 \mathrm{~h} /$ day, during 14 days. For $35 \%$ HP treatment, two sessions of 45 minutes each were employed. In intermediate periods specimens were stored in artificial saliva. Experimental groups $(n=19)$ were subdivided according to the simulation of pulpal pressure $(25 \mathrm{~mm} \mathrm{Hg}$ ) during bleaching treatment. Initial color measurement and after bleaching treatment were assessed by spectrophotometry, using CIE L*a*b* system. The data were statistically analyzed by ANOVA and Dunnett's posthoc tests $(p<0.05)$.
\end{abstract}

Results: There was significant difference of $\Delta E$ for all experimental groups compared to negative control group, according to Dunnett's test $(p<0.0001)$. There were no significant difference for total color variation $(\Delta \mathrm{E})$ among experimental groups $(p>0.05)$.

Conclusion: It was concluded that all bleaching gels showed bleaching efficacy compared to non-bleached group and that the simulated pulpal pressure did not influence the bleaching outcomes of the tested gels.

Clinical significance: Although numerous in vitro studies investigating the efficacy of bleaching agents have been performed, they do not properly simulate the pulpal pressure. In order to make these studies closer to clinical conditions, it

\footnotetext{
${ }^{1}$ Assistant Professor, ${ }^{2} \mathrm{PhD}$ Student, ${ }^{3} \mathrm{MSc}$ Student, ${ }^{4} \mathrm{Head}$ ${ }^{5}$ Chairman, ${ }^{6}$ Associate Professor

${ }^{1-3,6}$ Department of Restorative Dentistry, School of Dentistry UNESP, São Jose dos Campus, São Paulo, Brazil
}

${ }^{4}$ Department of Preventive Dentistry, Periodontology and Cariology, University of Göttingen, Göttingen, Germany

${ }^{5}$ Department of Preventive Dentistry, Periodontology and Cariology, University of Zürich, Plattenstrasse, Zürich Switzerland

Corresponding Author: Alessandra Bühler Borges, Assistant Professor, Department of Restorative Dentistry, Av. Engenheiro Francisco José Longo, 777, Jd. São Dimas, São José dos Campos, São Paulo-1245000, Brazil, e-mail: alessandra@ fosjc.unesp.br is important to reproduce these conditions in laboratory, so the results can be more reliable. This in vitro study was performed under simulated pulpal pressure, aiming to investigate its influence on dental bleaching outcomes.

Keywords: Dental bleaching, Simulated pulpal pressure, Bovine teeth.

How to cite this article: Borges $A B$, Batista GR, Arantes PT, Wiegand A, Attin T, Torres CRG. Influence of Simulated Pulpal Pressure on Efficacy of Bleaching Gels. J Contemp Dent Pract 2014;15(4):407-412.

Source of support: Nil

Conflict of interest: None declared

\section{INTRODUCTION}

Considered a conservative and simple treatment to change the tooth color, dental bleaching has been widely investigated in order to determine an appropriate protocol for obtaining satisfactory results, without undesirable damage to dental structures. $^{3}$

There are currently two main techniques for applying the bleaching gel on tooth, the in-office technique, which high-concentrated bleaching agents are applied directly on tooth by the clinician and the at-home technique, which the patient applies lower concentrated whitening gels in trays and makes use of them for a certain period of time. If properly controlled, both techniques are safe and effective. ${ }^{4}$

The most commonly used bleaching agents are hydrogen peroxide ( $\mathrm{HP}-\mathrm{H}_{2} \mathrm{O}_{2}$ ) and carbamide peroxide (CP). With both substances, however, the whitening agent is directly or indirectly $\mathrm{H}_{2} \mathrm{O}_{2}$, as it is the product resulting from the decomposition of CP. When the $\mathrm{H}_{2} \mathrm{O}_{2}$ decomposes into free radicals, the whitening reaction begins, since the released radicals oxidize the chromogens present inside dental tissues, breaking large aromatic chains, dark in color. These chains are transformed into linear chains that have unsaturated double bonds, which results in lighter color. Sequentially, these chains will undergo a second process of oxidation, which gives rise to linear chains saturated with single bonds, even more clear. ${ }^{40}$

In vitro studies are intended to simulate the conditions found clinically, however, the pulpal pressure is usually not simulated in the laboratory. Some laboratorial investigations using pulpal pressure simulation have been conducted, 
testing the bonding performance of adhesive systems, ${ }^{23}$ the detail reproducibility of impression materials, ${ }^{1}$ and the inward ions diffusion across dentin after dentifrice applications. ${ }^{26}$ However, as far as we know, there are no reported studies about the influence of pulpal pressure on the penetration of bleaching agents through the intercrystalline spaces of the enamel and dentin structure. It is supposed that the positive outward flow of dentinal fluid might resist the penetration of HP, and that could affect the extrapolation of results from laboratorial studies to the clinical condition. ${ }^{35}$

Thus, the investigation on the effect of simulated pulpal pressure on the outcome of in vitro tooth whitening may be a relevant factor. The purpose of this study was to evaluate the effect of pulpal pressure on the efficacy of tooth bleaching using $10 \%$ carbamide peroxide and $7.5 \% \mathrm{HP}$ gels according to the at-home technique, as well as the $35 \%$ HP according to the in-office technique. The null hypothesis investigated was that simulated pulpal pressure does not interfere in the efficacy of the different bleaching gels tested.

\section{MATERIALS AND METHODS}

\section{Specimens Preparation}

The methods described by Wiegand et $\mathrm{al}^{44}$ were used to prepare the specimens. Sixty-five extracted, non-damaged bovine intact incisors were stored in $0.1 \%$ thymol solution at room temperature until required. From each crown, two enamel-dentin specimens, $3 \mathrm{~mm}$ in diameter and $2.2 \mathrm{~mm}$ thick, were prepared from the labial surface with a trephine mill (Dentoflex, São Paulo, Brazil).

The lateral side of specimens was etched with $35 \%$ phosphoric acid (3M ESPE, St Paul, MN, USA) for 15 seconds, rinsed and dried with absorbent paper. Then, an adhesive system (Adper Single Bond, 3M ESPE) was applied with a disposable applicator both in lateral enamel and dentin sides of specimens and light cured for 10 seconds.

The specimens were then positioned in a silicon mold with a cavity $6 \mathrm{~mm}$ in diameter and $2 \mathrm{~mm}$ in depth. On the bottom of the mold, there was a second level cavity $3 \mathrm{~mm}$ in diameter and $0.1 \mathrm{~mm}$ in depth. The specimens were placed inside the internal cavity with the enamel surface to the bottom of the mold. The mold was filled with flowable resin (Opallis Flow, FGM Produtos Odontológicos, Joinvile, $\mathrm{SC}$, Brazil). On the side of the mold, there was a projection in the shape of a line which produced a lateral grove on the specimen. This helped to achieve the correct position at the time of the color reading (Fig. 1).

The specimens were attached to a metal holder and 0.1 $\mathrm{mm}$ of enamel was removed by polishing with sequential aluminum oxide abrasive papers (1200, 2400 and 4000 grit -FEPA-P; Struers, Ballerup, Denmark) in a polishing device
(DP-10, Panambra Industrial e Técnica SA, São Paulo, SP, Brazil) for 20 seconds each. The dentin side of specimens was abraded with a 1200 grit abrasive paper, removing 0.1 $\mathrm{mm}$ of dentin and resulting in specimens of $1 \mathrm{~mm}$ of enamel and $1 \mathrm{~mm}$ of dentin. The prepared specimens were examined under the stereomicroscope to certify the absence of cracks or other surface defects. The dentin was etched with $35 \%$ phosphoric acid (3M ESPE, St Paul, MN, USA) for $15 \mathrm{~s}$ and washed for 10 seconds for smear layer removal and tubules opening. After preparation, the specimens were stored in deionized water to avoid dehydration.

\section{Color Measurement}

Prior to treatment, the color of each specimen was assessed at standardized ambient conditions using a spectrophotometer CM-2600d (Konica Minolta, Osaka, Japan), which was set to small area view (SAV), where the reading area is $3 \mathrm{~mm}$, and the lighting area is $6 \mathrm{~mm}$. The color and spectral distribution were measured according to the CIE L*a* $\mathrm{b}^{*}$ system, using the Spectramagic NX software (Konica Minolta, Osaka, Japan). The standard illuminant D65 was set, also as the reflectance mode and the ultraviolet light was included. The observer angle was set to $2^{\circ}$ and the specular component was included (SCI). The samples were carefully dried with an absorbent paper (not desiccated) and immediately placed on the basis of the spectrophotometer, in a device that allow for exact and repeatable positioning of each specimen and color measurement under standardized ambient conditions.

The results of color measurement were quantified in terms of three coordinate values ( $\left.\mathrm{L}^{*}, \mathrm{a}^{*}, \mathrm{~b}^{*}\right)$ established by the Commission International de l'Eclariage (CIE), which locate color of an object in a three-dimensional color space. The $\mathrm{L}^{*}$ axis represents the degree of lightness within a sample and ranges from 0 (black) to 100 (white). The a* plane represents the degree of green/red color, while the $b^{*}$ plane represents the degree of blue/yellow within the sample. The spectrophotometer was set to make three consecutive readings, automatically calculating the mean values of

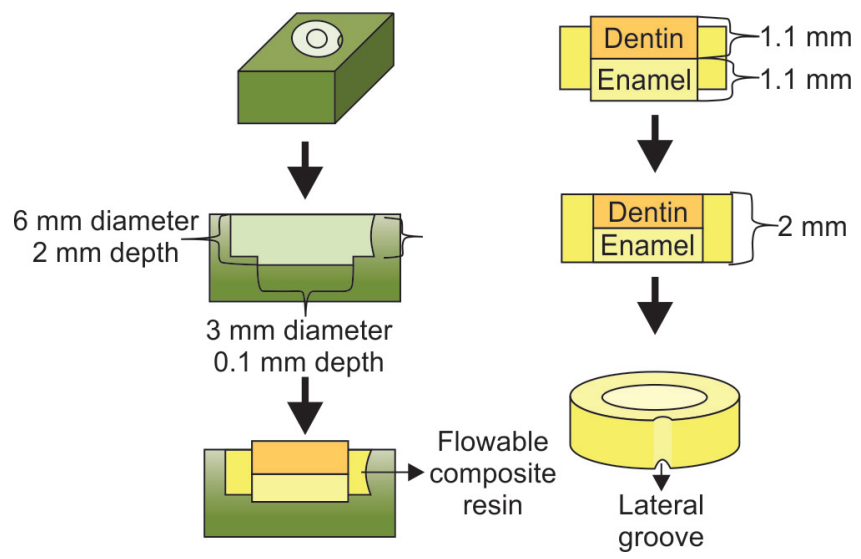

Fig. 1: Schematic draft preparation of the specimens 
$\mathrm{L}^{*} \mathrm{a}^{*} \mathrm{~b}^{*}$. Mean $\mathrm{L}^{*}$ value of each ED specimens was used for stratified allocation among groups.

\section{Groups Division}

The specimens were divided into four main groups: one negative control group $(\mathrm{n}=19$, without bleaching, storage in artificial saliva) and three experimental groups (each $\mathrm{n}=38)$ : 10\% CP-10\% carbamide peroxide gel (Whiteness Perfect 10\%-FGM Produtos Odontológicos, Joinvile, SC, Brazil); 7.5\% HP-7.5\% hydrogen peroxide gel (White Class 7.5\% FGM) and 35\% HP-35\% hydrogen peroxide gel (Whiteness HP-FGM). Each experimental group was subdivided into two subgroups (each $n=19$ ), with and without simulated pulpal pressure.

\section{Pulpal Pressure Simulation}

The method used to simulate pulpal pressure was described previously ${ }^{20}$ and adapted for this study. The specimens were set in chambers made with transparent epoxy resin (Arotec SA Ind e Com, Cotia, SP, Brazil). This chamber had two levels. The upper level presented the dimensions of $6 \mathrm{~mm}$ diameter and $1.5 \mathrm{~mm}$ depth. In the lower level, the chamber was narrower, with a diameter of $3 \mathrm{~mm}$ and depth of $3 \mathrm{~mm}$. Metal tubes were cemented in two sides of the bottom part of chamber, allowing the entrance and exit of the saline solution used to simulate pulpal fluid (Fig. 2).

When the specimens were set in the devices, $0.5 \mathrm{~mm}$ of enamel surface remained exposed out of the holder device. The edges of the specimens were then sealed with sticky wax. Saline was introduced inside the chambers, through the metal tubes cemented in the lateral sides of the chambers. For that, flexible silicon hoses with $2 \mathrm{~mm}$ of internal diameter and $4 \mathrm{~mm}$ of external diameter were connected in the metal tubes. These flexible hoses were coupled in an infusion bottle filled with saline, vertically placed $34 \mathrm{~cm}$ above the

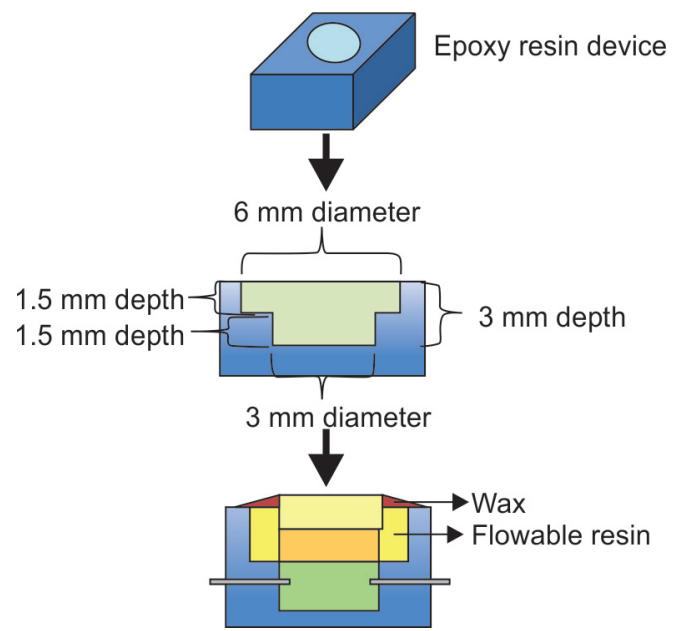

Fig. 2: Schematic draft device used to accommodate the specimens samples, to simulate the normal hydrostatic pressure of tooth, about $25 \mathrm{~mm} \mathrm{Hg}$ (Fig. 3). ${ }^{20,23}$ With the aid of a three-way valve, the whole system was evacuated using a vacuum pump (Prismatec 132, Itu, SP, Brazil) to eliminate the air bubbles of the simulated pulpal chamber. When the chamber was completely filled with saline, this tube through which the air was eliminated was kept closed, not allowing new incorporation of air bubbles.

Daily, the saline was drained from the chambers, by opening of the metal tube for 20 seconds, allowing the exit of the solution, so that the possible residual peroxide that eventually permeated through the bleached specimen could be removed.

\section{Bleaching Treatment}

After the specimens were set in the device used to simulate pulpal pressure, they received the bleaching treatments according to the at-home technique with $10 \% \mathrm{CP}$ (Whiteness Perfect, FGM Produtos Odontológicos) or 7.5\% HP (White Class, FGM Produtos Odontológicos), and in-office technique with 35\% HP (Whiteness HP, FGM Produtos Odontológicos).

For the at-home bleaching technique, the bleaching gel was deposited over the enamel surface, and remained in contact with the specimens for a period of 8 hours for $10 \%$ CP group and 1 hour for $7.5 \%$ HP group at controlled temperature $\left(25^{\circ} \mathrm{C}\right)$ and humidity $(50 \%)$. Thereafter, the gel was removed through a suction tube connected to a vacuum pump (Nevone, São Paulo, Brazil). The specimens were washed with water/air sprays and immersed in artificial saliva, during the intermediate periods (16 hours for $10 \% \mathrm{CP}$ and 23 hours for $7.5 \% \mathrm{HP}$ ). Subsequently, the gel application was repeated as described above for 14 days. After that period, the specimens were kept immersed in artificial saliva for a period of 7 days and the final color measurements were made.

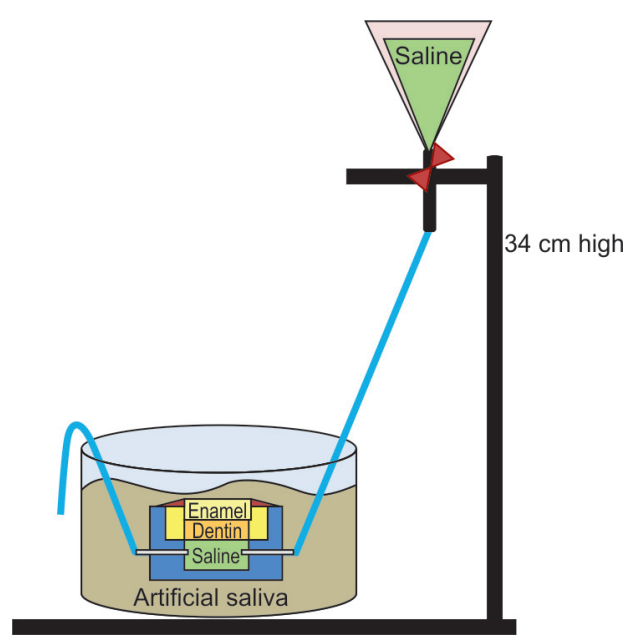

Fig. 3: Schematic draft device for simulation of pulpal pressure 
For the in-office bleaching technique (35\% HP group), a mixture of components from two bottles was prepared according to manufacturer's instruction and the bleaching gel was deposited over the enamel surface, remaining in contact with the specimens for a period of 45 minutes, changed every 15 minutes. Thereafter, the gel was removed through a suction tube connected to a vacuum pump (Nevone, São Paulo, Brazil). The specimens were rinsed with water/air sprays, and immersed in artificial saliva, during 7 days. The gel was then applied again for 45 minutes, as described above, simulating a two-session treatment. After that, the specimens were kept in artificial saliva for 7 days and final color measurements were made.

Artificial saliva was prepared according to the formulation of Göhring et $\mathrm{al}^{15}$ and consisted of hydrogen carbonate $(22.1 \mathrm{mmol} / \mathrm{l})$, potassium $(16.1 \mathrm{mmol} / \mathrm{l})$, sodium $(14.5$ $\mathrm{mmol} / \mathrm{l})$, hydrogen phosphate $(2.6 \mathrm{mmol} / \mathrm{l})$, boric acid $(0.8$ $\mathrm{mmol} / \mathrm{l})$, calcium $(0.7 \mathrm{mmol} / \mathrm{l})$, thiocyanate $(0.2 \mathrm{mmol} / \mathrm{l})$, and magnesium $(0.2 \mathrm{mmol} / \mathrm{l})$. The $\mathrm{pH}$ was adjusted to 7.0 .

Differences in values of $L^{*}(\Delta L), a^{*}(\Delta a)$ and $b^{*}(\Delta b)$, and the general change of color $(\Delta \mathrm{E})$ were automatically calculated by the software Spectramagic NX, using the following formula: $\Delta \mathrm{E} * \mathrm{ab}=\left[(\Delta \mathrm{L} *)^{2}+\left(\Delta \mathrm{a}^{*}\right)^{2}+\left(\Delta \mathrm{b}^{*}\right)^{2}\right] 0.5$.

\section{Statistical Analysis}

For statistical analysis, two-way analysis of variance (ANOVA) was used to compare $\triangle \mathrm{E}$ values obtained for the factors concentration (10\% CP, $7.5 \% \mathrm{HP}$ and $35 \%$ HP), pulpal pressure simulation (with and without) and the interaction between them. For identification of differences between the experimental and the control groups, one-way ANOVA followed by Dunnett's test were used. Statistical analysis was performed with the software Statistica for Windows (Statsoft, Tulsa, OK, EUA) with a significance level of $5 \%$.

\section{RESULTS}

Mean and standard deviation data of $\Delta \mathrm{E}$ parameter are presented in Table 1.

Table 1: Mean ( \pm standard deviation) data for different groups tested

\begin{tabular}{lll}
\hline Groups & Pulpal pressure & Delta $E^{*}$ \\
\hline Control & Without & $1.94 \pm 0.72^{\mathrm{a}}$ \\
$10 \% \mathrm{CP}$ & With & $4.89 \pm 1.07^{\mathrm{b}}$ \\
& Without & $4.73 \pm 0.85^{\mathrm{b}}$ \\
$7.5 \% \mathrm{HP}$ & With & $4.40 \pm 0.62^{\mathrm{b}}$ \\
& Without & $4.69 \pm 0.70^{\mathrm{b}}$ \\
$35 \% \mathrm{HP}$ & With & $4.31 \pm 0.84^{\mathrm{b}}$ \\
& Without & $4.41 \pm 0.84^{\mathrm{b}}$
\end{tabular}

${ }^{*}$ Different letters indicate significant differences among groups $(p<0.05)$
Two-way ANOVA revealed no significant effects for the bleaching groups $(\operatorname{Fdf}(2 ; 108)=2.23 ; \mathrm{p}$-value $=0.11)$ and the pulpal pressure $(\operatorname{Fdf}(1 ; 108)=0.52 ; \mathrm{p}$-value $=0.46)$. The interaction between the factors was also not significant (Fdf $(2 ; 108)=0.76 ; p$-value $=0.46)$. However, color change of all experimental groups was significantly different from the control $(p<0.0001)$, as revealed by Dunnett's test.

\section{DISCUSSION}

In this study, bovine teeth were used, as they are easier to obtain and standardize, considering the large amount of teeth required, and due to the ethical difficulties in obtaining healthy extracted human teeth. ${ }^{39}$ Bovine teeth are commonly used as substitute to human teeth, due to their great similarity with regard to chemical and physical properties, such as composition, density of enamel, and microhardness. ${ }^{13,37}$ Bovine and human substrates are also found to behave similarly in terms of staining and bleaching effects. ${ }^{2}$

Furthermore, bovine dentin allow better standardization of permeability conditions, considering the great variability of human dentin permeability characteristics, since the hydraulic conductance and diffusional water flux was shown to be similar between human and bovine dentin. ${ }^{34}$ Thus, bovine dentin near cementoenamel junction is considered a suitable alternative for coronal human dentin for in vitro studies investigating transdentinal permeability. ${ }^{34}$

According to Camargo et al, ${ }^{9}$ bovine teeth showed a reduced penetration of bleaching agent compared to human teeth, probably because of the dentin thickness, as diffusional rate varies according to dentin thickness. ${ }^{14,34}$ For this study, the thickness of enamel and dentin was standardized in $1 \mathrm{~mm}$ each, in order to reproduce the human maxillary incisors. ${ }^{17}$ Bovine dentin samples in disk shape were used before in perfusion studies, ${ }^{43}$ and they were considered adequate substitutes for this type of studies.

The bleaching technique for vital teeth involves the application of peroxide in different concentrations on the enamel surface. Enamel is a high-mineralized tissue, arranged in prisms. Only about $4 \%$ of enamel composition is organic material, distributed in the interprismatic area. ${ }^{16}$ Transenamel fluid flow has been previously demonstrated, ${ }^{6}$ as well as the penetration of small molecules through enamel tissue. ${ }^{18}$ The narrow tortuous pathways of enamel allow diffusion of molecules and very limited flow. Hydrogen peroxide can interact with both organic and inorganic materials, penetrating the enamel tissue along the intra- or inter-prismatic regions of enamel. The organic materials in these areas act as diffusion channels, allowing the penetration of the free radicals. ${ }^{24}$

On the other hand, the main morphological characteristic of dentin is its tubular structure, which connects the pulp to 
the enamel-dentin junction, and is filled by dentinal fluid, making it permeable. Dental procedures may alter the permeability of dentin and allow the movement of fluid in the tubules. ${ }^{27,31}$ Due to its low molecular weight, HP is able to penetrate throughout the inner structure of enamel and dentin and reach the pulp, which could result in different levels of injury to pulpal tissues. ${ }^{8,38}$ In vital teeth, pulpal fluid pressure is able to reduce the spread of chemicals into the pulp, ${ }^{22}$ and probably the amount of peroxide penetrating into the pulp is smaller than the amount found in in vitro studies, due to the limitations to reproduce exactly the in vivo conditions, as the natural defense mechanisms of pulpal tissues, ${ }^{42}$ and the individual variation of blood pressure.

There is a great variation in the values of hydrostatic pressure used to simulate the normal human pulpal pressure in laboratorial studies. ${ }^{10,32,36}$ In the present study, $25 \mathrm{~mm} \mathrm{Hg}$ was used, which corresponds to approximately $34 \mathrm{~cm} \mathrm{H}_{2} \mathrm{O}$, as recommended by previous studies..$^{20,30}$

Several laboratory studies have been conducted to evaluate the effectiveness of different bleaching agents and techniques without pulpal pressure simulation. ${ }^{12,41}$ In the present study, the null hypothesis was accepted, since the presence of pulpal fluid did not influence the results of the bleaching treatment.

It was previoulsly reported that the pressure does not oppose diffusion of substances through dentin and that the transdentinal pressure exert little effect on diffusion when the tubules are occluded. Alternatively, when the tubules are open and pressure is applied, the high outward flow effectively opposes the inward diffusion. ${ }^{28}$ Although both flow and diffusion are dependent on the width of the tubule, flow varies with the fourth power of the tubule radius while diffusion is proportional to the square of the radius. ${ }^{25}$ Due to these relationships, tubule oclusion hinders flow more than diffusion. As in the bleaching model used the dentin was covered by enamel, the diffusion of HP may not has been affected by pulpal pressure simulation.

Otherwise, although it is known that the enamel permeability is increased by the strong oxidizing action of HP on enamel proteins, ${ }^{33}$ it is still negligible to convective flow compared to dentin. Thus, simulated pulpal pressure, in fact, may excert a small effect on the penetration of bleaching agents on tooth structure, and further studies regarding this topic should be performed to determine the real risk of peroxide penetration causing pulpal injuries.

It must be considered, however, that this study evaluated the total color alteration after bleaching and not necessarily the penetration of HP through enamel and dentin. One might suppose that the bleaching gel penetrated only into enamel, and this was enough to produce lightening of the whole sample. In fact, the bleached enamel exhibits alterations in light reflectance. ${ }^{21}$ Nevertheless, based on the obvious color alterations obtained in bleached dentin, some authors suggested that the color of bleached teeth is highly influenced by the color change of the subsurface dentin. ${ }^{35,44}$

The method of color evaluation is important to ensure reliability of results. In this study, the spectrophotometric analysis was used, due to its great accuracy, reproducibility and objectivity. ${ }^{29}$ The results also showed that the three bleaching agents tested presented $\Delta \mathrm{E}$ values similar to each other and significantly higher than the non-bleached negative control group. In a previous clinical study, it was also observed similar efficacy for both $10 \% \mathrm{CP}$ and $35 \% \mathrm{HP}$ bleaching agents. ${ }^{5}$ In fact, the literature has shown that different concentrations of $\mathrm{CP}$ and $\mathrm{HP}$ bleaching agents result in similar bleaching outcomes, ${ }^{7,12,19}$ and that the results obtained with a shorter treatment time for high-concentrated agents are similar than that obtained with longer time for low-concentrated bleaching gels. ${ }^{3,11}$

\section{CONCLUSION}

According to the limitations of this study, it can be concluded that the simulation of pulpal pressure did not affect the bleaching outcomes for the three bleaching agents tested.

\section{ACKNOWLEDGMENTS}

The authors wish specially thank to Mrs Beatrice Sener, chief of chemistry laboratory of Center for Dental Medicine, University of Zürich, Department of Preventive Dentistry, Periodontology and Cariology, for her essential support developing the simulated pulpal pressure method used in this study and to FGM Produtos Odontológicos for providing the bleaching gels.

This study was supported by the State of São Paulo Research Foundation (FAPESP 09/54540-0).

\section{REFERENCES}

1. Acar O, Erkut S, Lakshmipathy M. Surface detail reproduction under simulated pulpal pressure: a three-dimensional optical profilometer and scanning electron microscopy evaluation. J Prosthet Dent 2012;108(2):102-113.

2. Attia ML, Aguiar FH, Mathias P, Ambrosano GM, Fontes CM, Liporoni PC. The effect of coffee solution on tooth color during home bleaching applications. Am J Dent 2009;22(3):175-179.

3. Auschill TM, Hellwig E, Schmidale S, Sculean A, Arweiler NB. Efficacy, side-effects and patients acceptance of different bleaching techniques (OTC, in-office, at-home). Oper Dent 2005;30(2):156-163.

4. Bernardon JK, Sartori N, Ballarin A, Perdigao J, Lopes GC, Baratieri LN. Clinical performance of vital bleaching techniques. Oper Dent 35(1):3-10.

5. Bernardon JK, Sartori N, Ballarin A, Perdigão J, Lopes GC, Baratieri LN. Clinical performance of vital bleaching techniques. Operative Dentistry 2010 Jan-Feb;35(1):3-10. 
6. Bertacci A, Chersoni S, Davidson CL, Prati C. In vivo enamel fluid movement. Eur J Oral Sci 2007;115(3):169-173.

7. Bizhang M, Chun YH, Damerau K, Singh P, Raab WH, Zimmer S. Comparative clinical study of the effectiveness of three different bleaching methods. Oper Dent 2009;34(6):635-641.

8. Bowles WH, Thompson LR. Vital bleaching: the effects of heat and hydrogen peroxide on pulpal enzymes. J Endod 1986; 12(3):108-112.

9. Camargo SE, Valera MC, Camargo CH, Gasparoto Mancini MN, Menezes MM. Penetration of 38\% hydrogen peroxide into the pulp chamber in bovine and human teeth submitted to office bleach technique. J Endod 2007;33(9):1074-1077.

10. Ciucchi B, Bouillaguet S, Holz J, Pashley D. Dentinal fluid dynamics in human teeth, in vivo. J Endod 1995;21(4):191-194.

11. da Costa JB, McPharlin R, Paravina RD, Ferracane JL. Comparison of at-home and in-office tooth whitening using a novel shade guide. Oper Dent 2010;35(4):381-388.

12. Dietschi D, Benbachir N, Krejci I. In vitro colorimetric evaluation of the efficacy of home bleaching and over-the-counter bleaching products. Quintessence Int 2010;41(6):505-516.

13. Esser M, Tinschert J, Marx R. Material characteristics of the hard tissues of bovine versus human teeth. Dtsch Zahnärztl Z 1998;53(5):713-717.

14. Fogel HM, Marshall FJ, Pashley DH. Effects of distance from the pulp and thickness on the hydraulic conductance of human radicular dentin. J Dent Res 1988;67(11):1381-1385.

15. Gohring TN, Zehnder M, Sener B, Schmidlin PR. In vitro microleakage of adhesive-sealed dentin with lactic acid and saliva exposure: a radioisotope analysis. J Dent 2004;32(3):235-240.

16. Gwinnett AJ. Structure and composition of enamel. Oper Dent 1992;Suppl 5(10):10-17

17. Harris EF, Hicks JD. A radiographic assessment of enamel thickness in human maxillary incisors. Arch Oral Biol 1998; 43(10):825-831.

18. Ikeda H, Suda H. Facilitatory effect of AC-iontophoresis of lidocaine hydrochloride on the permeability of human enamel and dentine in extracted teeth. Arch Oral Biol 2013;58(4):341-347.

19. Kielbassa AM, Beheim-Schwarzbach NJ, Neumann K, Nat R, Zantner C. In vitro comparison of visual and computer-aided pre- and post-tooth shade determination using various home bleaching procedures. J Prosthet Dent 2009;101(2):92-100.

20. Krejci I, Kuster M, Lutz F. Influence of dentinal fluid and stress on marginal adaptation of resin composites. J Dent Res 1993;72(2):490-494.

21. Markovic L, Fotouhi K, Lorenz H, Jordan RA, Gaengler P, Zimmer S. Effects of bleaching agents on human enamel light reflectance. Oper Dent 2010;35(4):405-411.

22. Matthews B, Vongsavan N. Interactions between neural and hydrodynamic mechanisms in dentine and pulp. Arch Oral Biol 1994;39 Suppl:87S-95S

23. Mitchem JC, Terkla LG, Gronas DG. Bonding of resin dentin adhesives under simulated physiological conditions. Dent Mater 1988;4(6):351-353.

24. Park HJ, Kwon TY, Nam SH, Kim HJ, Kim KH, Kim YJ. Changes in bovine enamel after treatment with a $30 \%$ hydrogen peroxide bleaching agent. Dent Mater J 2004;23(4):517-521.

25. Pashley DH. Dentin permeability: theory and practice. In: Spångberg L, editor. Experimental endodontics. Boca Raton, FL: CRC Press;1990. p. 20-45.
26. Pashley DH, Agee K, Zhang Y, Smith A, Tavss EA, Gambogi RJ. The effects of outward forced convective flow on inward diffusion of potassium across human dentin. Am J Dent 2002;15(4):256-261.

27. Pashley DH, Carvalho RM. Dentine permeability and dentine adhesion. J Dent 1997;25(5):355-372.

28. Pashley DH, Matthews WG. The effects of outward forced convective flow on inward diffusion in human dentine in vitro. Arch Oral Biol 1993;38(7):577-582.

29. Paul S, Peter A, Pietrobon N, Hammerle CH. Visual and spectrophotometric shade analysis of human teeth. J Dent Res 2002;81(8):578-582.

30. Prati C, Pashley DH, Montanari G. Hydrostatic intrapulpal pressure and bond strength of bonding systems. Dent Mater 1991;7(11):54-58.

31. Richardson D, Tao L, Pashley DH. Dentin permeability: effects of crown preparation. Int J Prosthodont 1991;4(3):219-225.

32. Sauro S, Pashley DH, Montanari M, Chersoni S, Carvalho RM, Toledano M, et al. Effect of simulated pulpal pressure on dentin permeability and adhesion of self-etch adhesives. Dent Mater 2007;23(6):705-713.

33. Schiavoni RJ, Turssi CP, Rodrigues AL Jr, Serra MC, Pecora JD, Froner IC. Effect of bleaching agents on enamel permeability. Am J Dent 2006;19(5):313-316.

34. Schmalz G, Hiller KA, Nunez LJ, Stoll J, Weis K. Permeability characteristics of bovine and human dentin under different pretreatment conditions. J Endod 2001;27(1):23-30.

35. Sulieman M, Addy M, Macdonald E, Rees JS. The bleaching depth of a $35 \%$ hydrogen peroxide based in-office product: a study in vitro. J Dent 2005;33(1):33-40.

36. Tao L, Pashley DH. Dentin perfusion effects on the shear bond strengths of bonding agents to dentin. Dent Mater 1989;5(3): 181-184.

37. ten Cate JM, Rempt HE. Comparison of the in vivo effect of a 0 and 1,500 ppm FMFP toothpaste on fluoride uptake, acid resistance and lesion remineralization. Caries Res 1986;20(3): 193-201.

38. Thitinanthapan W, Satamanont P, Vongsavan N. In vitro penetration of the pulp chamber by three brands of carbamide peroxide. J Esthet Dent 1999;11(5):259-264.

39. Torres CR, Wiegand A, Sener B, Attin T. Influence of chemical activation of a $35 \%$ hydrogen peroxide bleaching gel on its penetration and efficacy - in vitro study. J Dent 2010;38(10): 838-846

40. Torres CRG, Borges AB, Kubo C, Gonçalves S, Araújo R, Celaschi S, et al. Dental bleaching associated to LED/Laser hybrid sources. São Paulo: Editora Santos; 2007.

41. Travassos AC, Rocha Gomes Torres C, Borges AB, Barcellos DC. In vitro assessment of chemical activation efficiency during in-office dental bleaching. Oper Dent 2010;35(3): 287-294.

42. Tse CS, Lynch E, Blake DR, Williams DM. Is home tooth bleaching gel cytotoxic? J Esthet Dent 1991;3(5):162-168.

43. Wiegand A, Buchholz K, Werner C, Attin T. In vitro cytotoxicity of different desensitizers under simulated pulpal flow conditions. J Adhes Dent 2008;10(3):227-232.

44. Wiegand A, Vollmer D, Foitzik M, Attin R, Attin T. Efficacy of different whitening modalities on bovine enamel and dentin. Clinical Oral Invest 2005;9(2):91-97. 